2. Stepanenko A, Potapov EV, Hetzer R. Mechanica circulatory support in a patient with congenitally corrected transposition of the great arteries. J Thorac Cardiovasc Surg. 2013;146:243.

3. Huebler M, Stepanenko A, Krabatsch T, Potapov EV, Hetzer R. Mechanical circulatory support of systemic ventricle in adults with transposition of great arteries. ASAIO J. 2012;58(1):12-4.

http://dx.doi.org/10.1016/ j.jtcvs.2013.03.017

\section{MANAGEMENT OF DISTAL AORTIC COMPLICATIONS AFTER REPAIR OF ACUTE TYPE A AORTIC DISSECTION} To the Editor:

Masseli et $\mathrm{al}^{1}$ report the use of antegrade stent grafting to treat acute complications early after surgery for acute type A aortic dissection. The previously surgically sewn ascending or arch Dacron graft was used as the entry point to antegrade deploy a stent graft in 5 patients with contained rupture or malperfusion. In 1 patient, the stent graft was inserted to treat exsanguination at the distal total arch suture line at the end of the primary operation. In the remaining 4 patients, the treatment occurred a few days after the primary procedure.

More important, in their article, reopening of a fresh sternotomy to access the aorta in an unstable patient may be more expeditious than struggling through femoral access and wires manipulations in a dissected and malperfused descending and abdominal aorta. We congratulate the authors for getting out of trouble by thinking outside the usual "stent-graft box."

The availability of stent grafts gives all of us additional tools to deal with difficult problems that traditional methods may have been unable to control as well. More important, all cardiovascular surgeons should become sufficiently familiar with all potential options at their disposal.

However, we find it often difficult to justify the reluctance to perform some form of frozen elephant trunk (FET) to prevent most of the complications successfully treated herein. Growing experience with FET techniques has shown benefits in simplifying complex 2-stage aortic operations, stabilizing distal aortic lesions, avoiding reliance on a fragile aortic anastomosis, and potentially correcting distal malperfusion. ${ }^{2}$ Exclusion of the descending thoracic aorta with appropriate length stent grafting can decrease long-term aortic dilatation and rupture risk. ${ }^{3}$ In addition, the FET, when combined with a total arch replacement, can make the possibility of type I proximal endoleak and proximal migration nonexistent.

We would encourage a more elective use of antegrade stent grafting to avoid having to resort to the emergent bailouts described herein or, worse yet, risk losing patients from rupture or malperfusion after discharge from our units.

Eduard Quintana, MD Murat Ugur, MD Alberto Pochettino, MD Division of Cardiovascular Surgery Mayo Clinic Rochester, Minn

\section{References}

1. Masseli F, Wilhelm K, Probst C, Schiller W. Open antegrade aortic stent implantation after surgical treatment in type A aortic dissection. J Thorac Cardiovasc Surg. 2012;144:1527-30.

2. Tsagakis K, Pacini D, Di Bartolomeo R, Gorlitzer M, Weiss G, Grabenwoger M, et al. Multicenter early experience with extended aortic repair in acute aortic dissection: is simultaneous descending grafting justified? J Thorac Cardiovasc Surg. 2010;140:S116-20.

3. Pochettino A, Brinkman WT, Moeller P, Szeto WY, Moser W, Cornelius K, et al. Antegrade thoracic stent grafting during repair of acute DeBakey I dissection prevents development of thoracoabdominal aortic aneurysms. Ann Thorac Surg. 2009; 88:482-9.

$$
\text { http://dx.doi.org/10.1016/ }
$$$$
\text { j.jtcvs.2013.01.050 }
$$

\section{Reply to the Editor:}

In our original article, we described antegrade stent placement as a useful bailout strategy for complications arising after surgical treatment of acute type A dissections. ${ }^{1}$ In their letter to the editor, Quintana et al propose the frozen elephant trunk technique (FET) as the initial procedure to avoid complications and the need for bailout strategies, such as the one we presented, and argue that the benefits of the FET have been shown. The cited reference reports about a product-associated registry and the analysis of a subset of 68 procedures that have been performed in patients with acute type A aortic dissections. $^{2}$ A newer publication concerning this registry, the International E-vita open Registry, ${ }^{3}$ is reporting about 274 treated patients, containing 88 patients with acute type A aortic dissection. The mortality in this group was $18 \%$, and the overall rate of spinal cord injuries was $8 \%$. In our opinion, these reports with relatively small numbers give no evidence for benefits of the FET in relation to conventional techniques that we extended with the method we presented.

Nevertheless, in total arch replacement, the FET gives some theoretical advantages that could outweigh its possible disadvantages, such as longer circulatory arrest times, higher incidences of spinal cord ischemia, or device-related problems. The FET has to be further evaluated to answer these questions. Additional products and ongoing growing experience will help to find the right position for the FET, which was, until now, mainly bound to a single product.

\section{Franz Joseph Masseli, MD Wolfgang Schiller, MD \\ Clinic for Cardiac Surgery University Hospital Bonn Bonn, Germany}

\footnotetext{
References

1. Masseli F, Wilhelm K, Probst C, Schiller W. Open antegrade aortic stent implantation after surgical treatment in type A aortic dissection. J Thorac Cardiovasc Surg. 2012;144:1527-30.

2. Tsagakis K, Pacini D, Di Bartolomeo R, Gorlitzer M, Weiss G, Grabenwoger M, et al. Multicenter early experience with extended aortic repair in acute aortic dissection: is simultaneous descending grafting justified? J Thorac Cardiovasc Surg. 2010;140: S116-20.
} 